\title{
DENSIDADE DE DRENAGEM E SUA RELAÇÃO COM FATORES GEOMORFOPEDOLÓGICOS NA ÁREA DO ALTO RIO PARDO, SP E MG
}

\author{
Silvio Takashi HIRUMA \\ Waldir Lopes PONÇANO
}

\begin{abstract}
RESUMO
A densidade de drenagem é um dos principais parâmetros na análise morfométrica de bacias hidrográficas, correspondendo ao comprimento médio de canais de uma bacia por unidade de área. A distribuição espacial dos valores da densidade de drenagem na região do alto rio Pardo - situada entre a porção nordeste do Estado de São Paulo e sul de Minas Gerais - foi obtida a partir da medição de comprimentos de canais em celas quadráticas que recobriram toda área. Observou-se uma significativa correlação espacial das anomalias de alta densidade de drenagem com a distribuição das principais estruturas reativadas no Mesozóico-Cenozóico, sugerindo uma retomada erosiva das formas de relevo, devido à neotectônica. As principais anomalias de rarefação de drenagem foram observadas nos terrenos sedimentares da Bacia do Paraná. Uma menor correlação foi obtida com os solos, podendose observar uma tendência geral de concentração de zonas anômalas de alta densidade de drenagem nos solos podzólicos e baixa a intermediária nos latossolos. Os resultados indicam que o estudo desta variável morfométrica representa uma importante ferramenta na definição preliminar de áreas, nas quais se podem buscar evidências estruturais e tectônicas de campo com maior probabilidade de êxito.
\end{abstract}

\begin{abstract}
Drainage density is one of the main parameters of morphometric analysis in hydrographic basins, corresponding to the average length of channels in the basin per unit of area. The spacial distribution of drainage density values in the upper course of Pardo river area, in the northeast of the state of São Paulo and southern Minas Gerais, was obtained measuring channel lengths in quadratic cells, covering all the area. An important spacial correlation was observed between anomalies of high drainage density and the distribution of main structures reactivated in the Mesozoic - Cenozoic, which suggests an increase of erosive processes controlled by neotectonics. The main anomalies of rarefaction of drainage were observed on sedimentary areas of the Parana Basin. A lower correlation was obtained with the soils, where is observed a general trend to high density drainage anomalous zones in podzolic soils and low to intermediate in latosols. The results indicate that the study of this morphometric parameter represents an important tool for the preliminary definition of areas, which may provide structural and tectonic evidence in field works with more probability of success.
\end{abstract}

\section{INTRODUÇÃO}

A densidade de drenagem, reconhecida como um dos mais importantes parâmetros da análise morfométrica de bacias hidrográficas, foi definida inicialmente por HORTON (1945) como o comprimento médio de rios de uma bacia hidrográfica por unidade de área, podendo ser expressa pela equação: $D d=\Sigma L / A$, onde $D d$ é a densidade de drenagem, $\Sigma L$, o comprimento total de canais e $A$, a área da bacia. HORTON (1945) destacou dois importantes fatores que determinariam a $D d$, além do regime de chuvas e do relevo, que seriam a capacidade de infiltração do solo e a resistência inicial do terreno à erosão.

CHRISTOFOLETTI $(1979,1981)$ analisou diversos trabalhos que discutem a variabilidade espacial e temporal da $D d$ e suas possíveis correlações com diversas variáveis do meio físico, tais como: litologia, relevo, clima, cobertura vegetal e tipos de solo. $\mathrm{O}$ estudo de parâmetros morfométricos - inclusive da $D d-$ para a caracterização de tipos de solos foi 
muito difundido nas décadas de 1960/1970, principalmente nas escolas de agronomia (ESPÍNDOLA \& GARCIA, 1978; FRANÇA, 1968).

Avaliando-se os trabalhos citados anteriormente, nota-se que a tentativa de se correlacionar a $D d$ com os fatores do meio físico permanece ainda como um assunto de extrema complexidade, uma vez que tais fatores interagem concomitantemente e com diferentes pesos.

O presente trabalho tem por objetivo correlacionar qualitativamente a $D d$ com dados geológico-estruturais, geomorfológicos e pedológicos, a partir da comparação de mapas temáticos com mapas de isovalores de $D d$. Pretende também avaliar o potencial do mapeamento desta variável morfométrica como auxiliar nas investigações de caráter regional (cf. DEFFONTAINES, 1989, por exemplo).

Esta pesquisa integra um conjunto de estudos visando definir o quadro dos processos erosivos e neotectônicos de uma extensa região $\left(\right.$ cerca de $13.000 \mathrm{~km}^{2}$ ) situada entre a porção nordeste do Estado de São Paulo e sul de Minas Gerais, que engloba toda a bacia de captação do alto rio Pardo, a montante da barragem da UHE Armando de Sales Oliveira (Fig. 1).

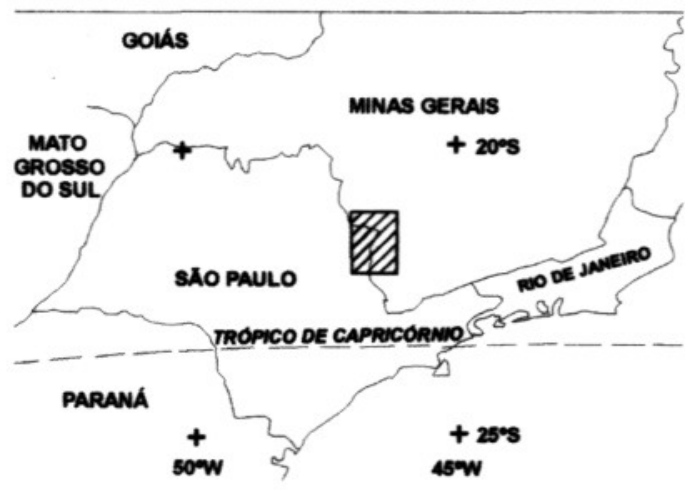

FIGURA 1 - Localização da área de estudo.

\section{CONTEXTO GEOLÓGICO E GEOMORFOLÓGICO}

A bacia hidrográfica do alto rio Pardo situa-se no Maciço de Guaxupé, constituído por granulitos migmatizados e intrudidos por granitos (ALMEIDA et al., 1976) (Fig. 2). Corresponde, segundo MELO et al. (1993), a terrenos antigos de alto grau metamórfico, de natureza predominantemente alóctone, bordejados por uma faixa de dobramentos mais jovem (faixa alto rio Grande). Suas rochas são polideformadas e de evolução policíclica, estando afetadas por migmatização e anatexia do Proterozóico Superior, e encaixam rochas granitóides intrusivas tardi a pós-tectônicas do Proterozóico Médio a Eopaleozóico.

O limite oeste do Maciço de Guaxupé corresponde ao limite erosivo com os sedimentos paleozóicos e vulcânicas mesozóicas associadas da Bacia do Paraná (Fig. 2).

A região do alto Pardo foi afetada por intenso magmatismo alcalino, representado por intrusivas hipoabissais e lavas efusivas, durante o Cretáceo Superior. O maciço de Poços de Caldas, incluído na Província de mesmo nome (ALMEIDA, 1983), constitui o melhor exemplo.

A área não apresenta acumulações expressivas de depósitos cenozóicos. Estes ocorrem como coberturas sedimentares relativamente delgadas e descontínuas, sendo representadas em sua maior parte por cascalhos em terraços fluviais, depósitos colúvio-aluviais, coluviões e aluviões.

Quanto às suas características geomorfológicas, o IPT (1992) identificou quatro níveis planálticos delimitados a partir de rupturas de declividade positivas e negativas de expressão regional. Cada nível foi correlacionado a uma superfície erosiva, como discriminado a seguir:

- planaltos subnivelados pela superfície cimeira $(A)$ : a mais antiga e elevada da região, com altitude máxima de 1.764 metros. Apresenta várias situações sugestivas de deformação por falhas e caimento principal no sentido da antiga drenagem conseqüente (para noroeste) (Fig. 2);

- planaltos subnivelados por superfície intermediária $(I)$ : possui cotas de até 1.360 metros e apresenta limites erosivos com controle litológico, evidências locais de controle tectônico indicadas por variações altimétricas e soleiras fluviais condicionadas por estruturas geológicas;

- primeiro nível de planaltos rebaixados (B): suas cotas atingem 960 metros, com nítido contorno erosivo e controle litológico. Desenvolve-se ao longo dos principais cursos d'água sobre rochas cristalinas;

- segundo nível de planaltos rebaixados $(B d)$ : apresenta cotas máximas de 800 metros e nítido controle erosivo e litológico, relacionado às calhas de drenagem em áreas de colinas sedimentares da Bacia do Paraná. 


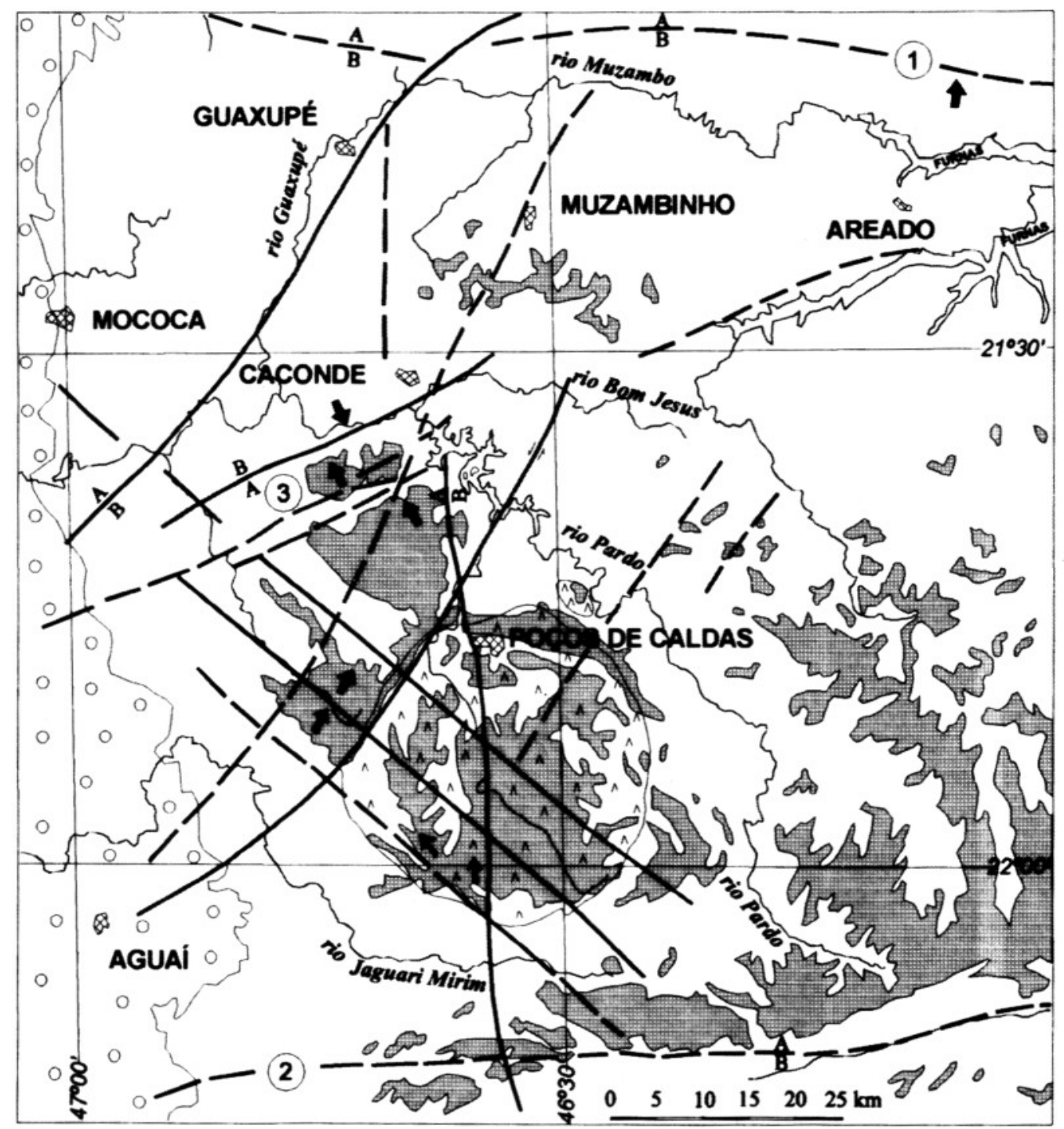

Maciço de Guaxupé

Sedimentos e vulcânicas associadas da Bacia do Paraná

Maciços alcalinos de Poços de Caldas e Boa Vista

Limite do nivel planáltico associado à superficie cimeira ( A )
Principais estruturas reativadas no Mesozb́ica-Cenozbico

(1) Zona de cisalhamento de Campo do Meio

(2) Zona de cisalhamento de Ouro Fino

(3) Sistema de falhas do rio Pardo 


\section{METODOLOGIA}

Os procedimentos tradicionais, para a aquisição de dados necessários ao cálculo da $D d$, envolvem o uso de curvímetros e planímetros, que os tornam freqüentemente demorados e cansativos, além de estarem sujeiros a erros do mensurador. Tendo em vista estas dificuldades, CHRISTOFOLETTI \& FILIZOLA (1978) apresentaram uma série de procedimentos expeditos para o cálculo da $D d$.

A medição de comprimentos de canais foi realizada, neste trabalho, com o auxílio do equipamento eletrônico do tipo "Mini-Mop" que executa as mesmas tarefas de um curvímetro e/ou planímetro (PAULON, 1988). Tal procedimento agilizou muito o trabalho de coleta de dados.

Efetuou-se, inicialmente, a montagem em escala 1:100.000 da rede de drenagem da área estudada, a partir da redução de cartas topográficas de escala 1:50.000 do IBGE. Sabe-se que a representação do relevo nas cartas 1:50.000 possui imperfeições, tanto devido aos procedimentos de harmonização impostos pelo cartógrafo ao traçado das curvas de nível como aquelas decorrentes da própria restituição das fotos aéreas (cf. PONÇANO et al., 1989). Espera-se que a redução dessas cartas para 1:100.000 possa ter atenuado tais deficiências.

$\mathrm{O}$ uso de uma rede de amostragem formada por celas quadráticas de $4 \times 4 \mathrm{~km}^{2}$ mostrouse mais adequado para a coleta de dados, em função da escala de trabalho utilizada (1:100.000), e também para que fosse possível o recobrimento total da área, que resultou em um total aproximado de 800 celas. Para cada uma destas, foram medidos os comprimentos dos cursos de água e calculado o valor da densidade de drenagem $(D d)$ pela fórmula $D d=$ $\Sigma L / A$, onde $\Sigma L$ representa a somatória dos comprimentos dos canais contidos na cela (em $\mathrm{km})$ e $A$, a área da cela $\left(\mathrm{em} \mathrm{km}^{2}\right)$.

O mapa de isovalores de $D d$ foi gerado pelo programa de sistema de informação geográfica (SIG) desenvolvido pelo INPE/ENGESPAÇO. Nas áreas de represas, onde a coleta de dados não foi possível, a interpolação foi feita a partir das celas vizinhas.

A separação em diferentes classes de valores de $D d$ obedeceu aos seguintes critérios estatísticos:

- classe de valores acima de média + desvio-padrão, aqui referida como valores anômalos superiores;

- classe de valores dentro do intervalo média + desvio padrão e média - desviopadrão, aqui referida como valores intermediários;
- classe de valores abaixo de média desvio-padrão, aqui referida como valores anômalos inferiores.

Finalmente, através de sobreposição, foram feitas comparações entre o mapa de isovalores de $D d$ e os mapas geológico/estrutural, geomorfológico e pedológico.

\section{RESULTADOS OBTIDOS}

Os valores de $D d$ obtidos foram agrupados em três classes:

- valores anômalos superiores $(D d>2,50$ $\mathrm{km} / \mathrm{km}^{2}$ );

- valores intermediários $\left(1,25 \mathrm{~km} / \mathrm{km}^{2}<\right.$ $\left.D d<2,50 \mathrm{~km} / \mathrm{km}^{2}\right)$

- valores anômalos inferiores $(D d<1,25$ $\mathrm{km} / \mathrm{km}^{2}$ ).

As melhores correlações espaciais resultaram dos mapas de principais estruturas e de litotipos e, em segundo lugar, do de solos.

\section{1 $D d \times$ principais estruturas}

As zonas de anomalias superiores de densidade de drenagem $\left(D d>2,50 \mathrm{~km} / \mathrm{km}^{2}\right)$ coincidem com os principais trends de estruturas, onde foram detectadas evidências de reativação de idades mesozóica e cenozóica, descritos por MELO et al. (1993) (Fig. 3):

- trends de direção aproximada $\mathrm{E}-\mathrm{W}$, que correspondem às zonas de cisalhamento de Ouro Fino, no extremo sul da área, e Campo do Meio, no extremo norte;

- trend de direção WSW-ENE, correspondente ao sistema de falhas do rio Pardo;

- trend de direção SW-NE;

- trend de direção N-S;

- trend de direção NW-SE.

Estas concentrações de altos valores de $D d$ refletem uma retomada erosiva das formas de relevo ao longo das direções das estruturas citadas, possivelmente atribuída à geração de descontinuidades e basculamentos provenientes da atividade tectônica recente. Essa retomada erosiva pode ter gerado a expansão da rede de drenagem e, conseqüentemente, um aumento da $D d$.

Segundo MELO et al. (1993), o controle tectônico na organização da rede de drenagem pode ser observado pelo desenvolvimento da drenagem de caráter subseqüente ao longo das estruturas de direções E-W a ENE-WSW (cinturão de cisalhamento de Ouro Fino) no extremo sul da área, WNW-ESE (cinturão de cisalhamento de Campo do Meio) no extremo norte e ENE-WSW/NE-SW a norte e noroeste da faixa central. 


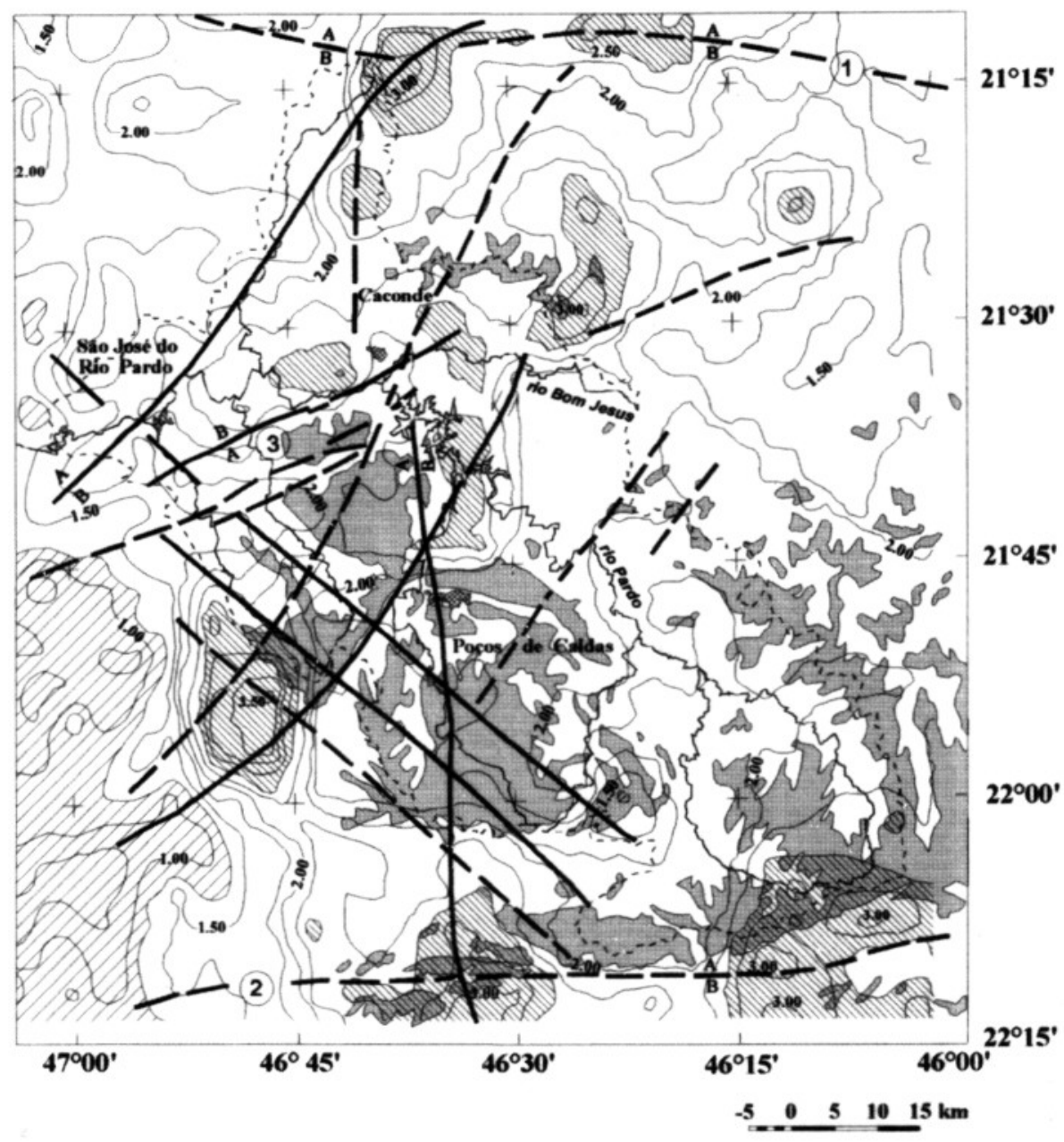

\section{CLASSES DE VALORES DE DENSIDADE DE DRENAGEM $\left(E M \mathrm{~km} / \mathrm{km}^{2}\right)$ :}

Valores anômalos superiores ( $\mathrm{Dd}>2,50$ )

Valores intermediários $(2,50>\mathrm{Dd}>1,25)$

¿ Valores anômalos inferiores ( $\mathrm{Dd}<1,25$ )

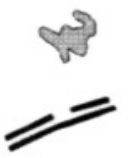

Limite do nivel planáltico associado à superficie cimeira

Principais estruturas reativadas no Mesozóico - Cenozóico

(1) Zona de cisalhamento de Campo do Meio

(2) Zona de cisalhamento de Ouro Fino

(3) Sistema de falhas do rio Pardo

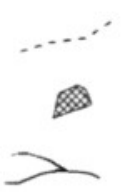

Limite da bacia do alto rio Pardo

Cidades principais

Drenagens principais da bacia do alto rio Pardo

FIGURA 3 - Correlação qualitativa entre a densidade de drenagem e as principais estruturas reativadas no Mesozóico-Cenozóico na região do alto rio Pardo (estruturas extraídas de MELO et al., 1993). 
A região do rio Bom Jesus representa uma área anômala do ponto de vista geomorfológico, apresentando, além dos aluviões em planícies, restos de terraços relativamente elevados que sugerem significativa mudança do nível de base, possivelmente relacionada a movimentações tectônicas (IPT, 1992). O trecho médio inferior do rio Bom Jesus coincide com uma zona de altos valores de $D d$.

A região compreendida entre as cidades de São José do Rio Pardo, Caconde e Poços de Caldas apresenta valores intermediários de $D d$, embora esteja situada no cruzamento dos sistemas de falhas SW-NE e WSW-ENE. Isto se deve ao fato de que nessa região ocorre um planalto de topo aplainado, relativamente menos dissecado, correspondente a uma porção da superfície cimeira regional - correlacionável à Superfície Sul-Americana de KING (1956) - onde os processos de retomada erosiva e de expansão da rede de drenagem não foram tão expressivos. Este planalto apresenta-se delimitado por três sistemas de falhas de caráter normal de direções WSW-ENE, N-S e SE-NW.

A região do maciço de Poços de Caldas, caracterizada pela presença de setores preservados da superfície $A$, nitidamente controlados pela litologia (MELO et al., 1993), também apresenta valores intermediários de $D d$, apesar de estar localizada no cruzamento das estruturas N-S e NW-SE.

\subsection{Dd x litotipos}

Os valores anômalos inferiores de $D d$ $\left(<1,25 \mathrm{~km} / \mathrm{km}^{2}\right)$ estão concentrados nos terrenos sedimentares da Bacia do Paraná, representados pela Formação Aquidauana (Subgrupo Itararé). Correspondem a diamictitos, siltitos arenosos e arenitos de coloração avermelhada.

Do ponto de vista estritamente litológico, não foi possível explicar a distribuição das anomalias encontradas nos terrenos pré-cambrianos.

CHRISTOFOLETTI (1970) realizou um detalhado estudo morfométrico de bacias hidrográficas na região do Planalto de Poços de Caldas, utilizando basicamente mapas topográficos de escala 1:10.000. A partir da análise em bacias representativas dos principais tipos litológicos encontrados na região, o autor verificou que os litotipos surgiam como condicionantes mais importantes no controle da $D d$; o relevo surgia apenas como um fator de variação. $\mathrm{Na}$ área do alto rio Pardo, entretanto, a $D d$ parece estar refletindo as estruturas mais regionais.

\section{3 $D d x$ solos}

Para fins de comparação entre a $D d$ e os tipos de solos da região do alto Pardo, foi utilizado o levantamento pedológico de escala $1: 1.000 .000$ do projeto RADAMBRASIL (1983).

A correlação da $D d$ com os tipos de solos, apesar de menos evidente do que com as principais estruturas, apresenta as seguintes tendências gerais (Fig. 4):

- os menores valores de $D d(<1,25$ $\mathrm{km} / \mathrm{km}^{2}$ ) encontram-se nos latossolos da Depressão Periférica, cujo substrato são os terrenos sedimentares da Bacia do Paraná. Caracterizados pela presença de horizonte B latossólico, estes solos são geralmente espessos e se desenvolvem sobre relevos planos a pouco ondulados. São comumente permeáveis, o que proporciona uma baixa razão deflúvio/infiltração. Desta maneira, as áreas de ocorrência deste tipo de solo geralmente apresentam baixa densidade de drenagem;

- as demais áreas de latossolos, localizadas em terrenos cristalinos de relevo mais dissecado, com maiores amplitudes topográficas, apresentam, em sua maioria, valores de $D d$ intermediários;

- os maiores valores de $D d(>2,50$ $\mathrm{km} / \mathrm{km}^{2}$ ) possuem uma tendência de concentração nas áreas de solos podzólicos. Caracterizados pela presença de horizonte B textural, estes solos apresentam espessuras menores que os latossolos e se desenvolvem sobre relevos mais ondulados e com maiores declividades. Geralmente, são solos mais impermeáveis que permitem um maior escoamento superficial e, conseqüentemente, a formação de novos canais (aumento da $D d$ ).

As observações citadas anteriormente confirmam os resultados apresentados por ESPÍNDOLA \& GARCIA (1978). Na compilação efetuada por estes autores, os latossolos apresentam, de maneira geral, valores de $D d$ sensivelmente menores que os dos solos podzólicos.

Cabe ressaltar que o mapa de solos compilado a partir do projeto RADAMBRASIL (1983) pode ser impreciso quanto aos limites de classes de solos, em virtude da transposição da escala 1:1.000.000 para a escala de trabalho deste estudo.

\section{4 $D d$ x níveis planálticos}

Observa-se que uma parte dos valores anômalos superiores de $D d$ ocorrem sobre áreas com rupturas de declives, nas transições entre os níveis planálticos. No entanto, este tipo de 


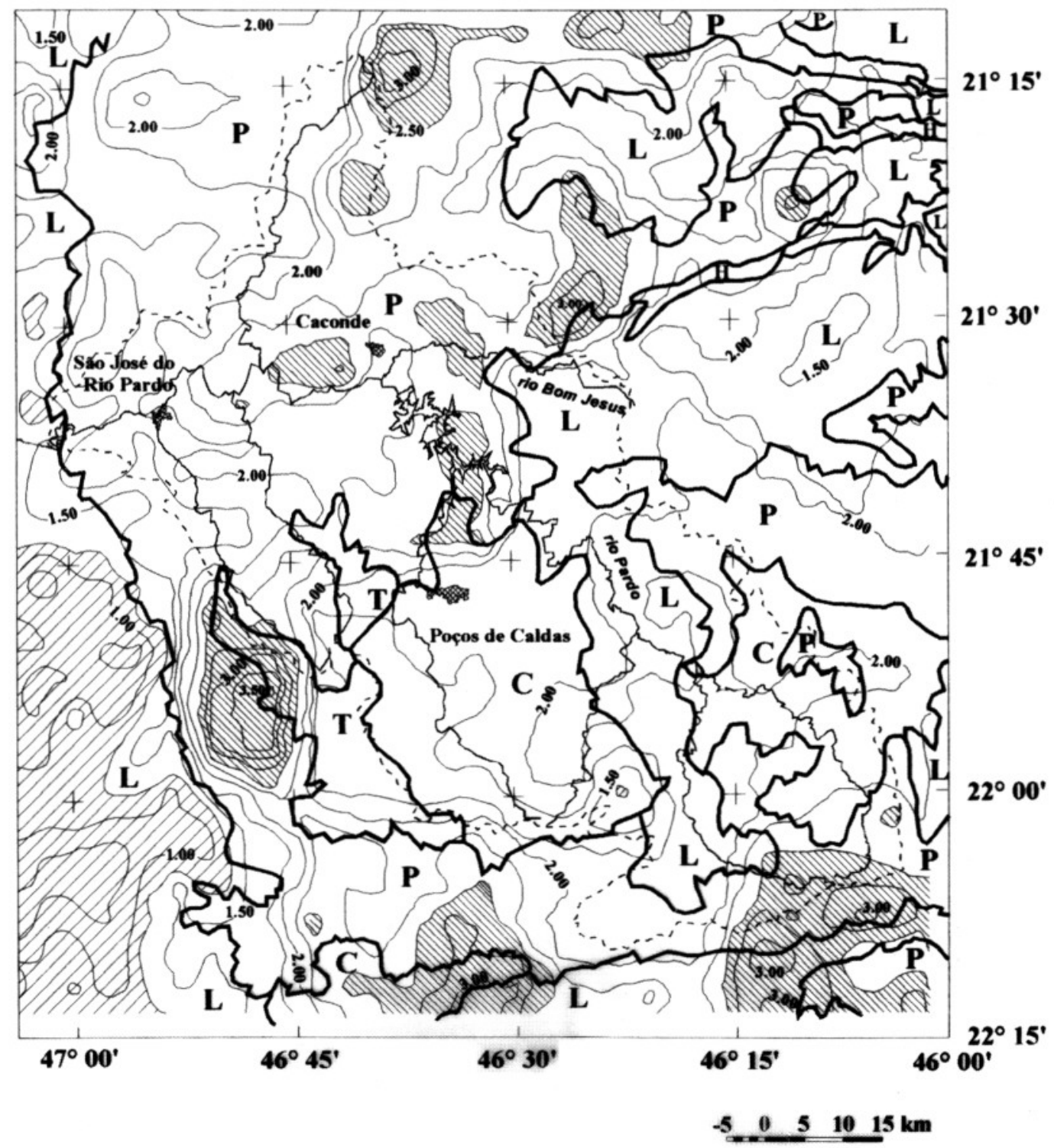

\section{CLASSES DE VALORES DE DENSIDADE DE DRENAGEM $\left(\right.$ EM $\left.\mathrm{km} / \mathrm{km}^{2}\right)$ :}

$\mathbb{N}$ valores anômalos superiores ( $\mathrm{Dd}>2,50$ )

$\square$ valores intermediários ( 2,50 $>$ Dd $>1,25)$

$\square$ valores anômalos inferiores ( $\mathrm{Dd}<1,25$ )

- limite entre grupos de solos:

$\mathrm{L}=$ Latossolos

$\mathbf{P}=$ Podzólicos

$\mathrm{T}=$ Terra Bruna

$\mathrm{C}=$ Cambissolos

$\mathbf{H}=$ Glei pouco húmico

..... limite da Bacia do alto rio Pardo

cidades principais

$>$ drenagens principais da bacia

FIGURA 4 - Correlação qualitativa entre a densidade de drenagem e os tipos de solos na região do alto rio Pardo (tipos de solos extraídos de RADAMBRASIL, 1983). 
correlação não é muito significativo, uma vez que possui caráter local.

Como já mencionado anteriormente, estão presentes porções da superficie cimeira regional $(A)$ que não teriam sofrido, com a mesma intensidade, os processos de retomada erosiva (Fig. 3).

\section{CONCLUSÕES}

A distribuição das anomalias de densidade de drenagem na bacia do alto rio Pardo obedece aos seguintes padrões:

- os valores anômalos inferiores de Dd concentram-se nos latossolos da Depressão Periférica, cujo substrato são os terrenos sedimentares da Formação Aquidauana. A presença de solos e rochas permeáveis em terrenos de topografia suave deve ter possibilitado uma menor razão deflúvio/infiltração, que teve reflexos nos baixos valores de $D d$;

- os valores anômalos superiores de $D d$ estão associados à distribuição dos principais trends de estruturas reativadas durante o Mesozóico-Cenozóico. Uma hipótese aceitável é a de ter havido uma reativação tectônica responsável por uma retomada erosiva, que teria provocado o entalhamento e adensamento da rede de canais;
- uma correlação espacial de menor grau é obtida entre os valores anômalos superiores de Dd e os solos podzólicos, que, por serem menos permeáveis que os latossolos - pela presença do horizonte argílico -, condicionam um maior escoamento superficial e, conseqüentemente, promovem o adensamento da drenagem, com a abertura de novos canais;

- localmente, observa-se que anomalias superiores de $D d$ coincidem com áreas de rupturas de declives, nas transições entre níveis planálticos.

Levando-se em conta o conjunto das investigações realizadas no Alto Pardo, as correlações obtidas entre densidade de drenagem e estruturas mostram que essa variável morfológica pode ser utilizada de modo expedito na definição preliminar de áreas, onde se podem buscar evidências estruturais e tectônicas de campo com maior probabilidade de êxito.

\section{AGRADECIMENTOS}

Os autores agradecem aos geólogos Dirceu Pagotto Stein e Mário Sérgio de Melo da Divisão de Geologia do Instituto de Pesquisas Tecnológicas do Estado de São Paulo, pelas sugestões e discussões que contribuíram para o desenvolvimento deste trabalho.

\section{REFERÊNCIAS BIBLIOGRÁFICAS}

ALMEIDA, F.F.M. de. 1983. Relações tectônicas das rochas alcalinas mesozóicas da região meridional da plataforma SulAmericana. Rev. Bras. Geoc., 13(3): 139-158.

ALMEIDA, F.F.M. de; HASUI, Y.; NEVES, B.B. de B. 1976. The upper Precambrian of South America. Bol. IG-USP, 7: 4580.

CHRISTOFOLETTI, A. 1970. Análise morfométrica das bacias hidrográficas do planalto de Poços de Caldas (MG). Tese de Livre-Docência, Cadeira de Geografia do Brasil, Faculdade de Filosofia, Ciências e Letras de Rio Claro, 215 p.

1979. A análise da densidade de drenagem e suas implicações geomorfológicas. Geografia, 4(8): 23-42.

1981. A variabilidade espacial e temporal da densidade de drenagem. Not. Geomorfol., 21(42): 3-22.
CHRISTOFOLETTI, A. \& FILIZOLA, H.F. 1978. Procedimentos expeditos para o cálculo da densidade de drenagem. Bol. Geogr., 36(256): 96-104.

DEFFONTAINES, B. 1989. Proposition of a morpho-neotectonic method: application in the Fougères area, Oriental Britany, France. Bull. INQUA N.C.12, p. $48-52$.

ESPÍNDOLA, C.R. \& GARCIA, G.J. 1978. Interpretação fotográfica de redes de drenagem em diferentes categorias de solos. Not. Geomorfol., 19(37/38): 29-40.

FRANÇA, G.V. de. 1968. Interpretação fotográfica de bacias e de redes de drenagem aplicada a solos da região de Piracica$b a$. Tese de Doutoramento, ESALQ/USP, Piracicaba, $151 \mathrm{p}$.

HORTON, R.E. 1945. Erosional development of streams and their drainage basins: hydrophysical approach to quantitative 
morphology. Geol. Soc. Amer. Bull., 56 (3): $275-370$.

IPT - INSTITUTO DE PESQUISAS TECNOLÓGICAS DE SÃO PAULO. 1992. Sismotectônica e dinâmica superficial na área do alto rio Pardo (SP e MG). São Paulo. Relatório IPT $\mathrm{n}^{\circ} 30.074$, 4 vols.

KING, L.C. 1956. A geomorfologia do Brasil Oriental. Rev. Bras. Geogr., 18(2): 147265.

MELO, M.S. de; STEIN, D.P.; PONÇANO, W. L.; BISTRICHI, C.A. 1993. Neotectônica da área do alto rio Pardo (SP e MG). Rev. Inst. Geol., 14(2): 27-38.
PAULON, N. 1988. Métodos quantitativos de análise de imagens geológicas. Relatório IPT no 26.201.

PONÇANO, W. L.; MELO, M.S. de; CHRISTOFOLETTI, A. 1989. Relações entre deflúvios e variáveis morfométricas em bacias hidrográficas do Estado de São Paulo. Rev. Bras. Geoc., 19(2):197-206.

RADAMBRASIL. 1983. SECRETARIA GERAL - MINISTÉRIO DE MINAS E ENERGIA. Projeto RADAMBRASIL; folhas SF. 23/24, Rio de Janeiro/Vitória: pedologia, geomorfologia, 1:1.000.000. Rio de Janeiro (Levantamento de Recursos Naturais).

Endereço dos autores:

Silvio Takashi Hiruma - Secretaria do Meio Ambiente - Instituto Geológico - Avenida Miguel Estéfano, 3.900 - Água Funda - 04301-903 - São Paulo, SP - Brasil.

Waldir Lopes Ponçano - Instituto de Pesquisas Tecnológicas do Estado de São Paulo - IPT - Cidade Universitária Armando Salles Oliveira - Caixa Postal 7141 - 05508-901 - São Paulo, SP - Brasil. 